\title{
Нанотехнологии - реальность современной стоматологии (обзор литературы)
}

Блинова А.В., Румянцев В.А.

Федеральное государственное бюджетное образовательное учреждение высшего образования «Тверской государственный медицинский университет» Министерства здравоохране-ния Российской Федерации, Тверь, Россия

\begin{abstract}
Резюме
К наночастицам относят высокодисперсные твердофазные объекты, размеры которых колеблются в границах от 1 до 100 нм. Технологии, в которых такие частицы применяются, получили название нанотехнологий. Поскольку этот сегмент научных поисков достаточно молодой, стоматологи еще не очень хорошо ориентируются в вопросах возможностей практического применения нанотехнологий, не знакомы с их преимуществами и перспективами внедрения. Сегодня активно происходит интеграция накопленных теоретических знаний в том числе в стоматологию. Эксперты размышляют над новыми путями решения актуальных профессиональных проблем. Насколько успешным будет процесс интеграции узкопрофильных исследований в практическую деятельность покажет только время. Разработка новых и внедрение существующих нанотехнологичныхмедицинскихметодикперспективное направление развития современной стоматологии.

Цель. Изучить перспективные сферы применения нанотехнологий в стоматологии, существующие методы диагностики, лечения и профилактики стоматологических заболеваний, основанные на свойствах наночастиц, обобщить научную литературу, посвященную данной проблеме.
\end{abstract}

Ключевые слова: нанотехнологии в стоматологии, кариес, эндодонтия, пародонтология, коррекция иммунитета, онкология, имплантация.

Статья поступила: 20.02.2020; исправлена: 15.04.2020; принята: 09.05.2020.

Конфликт интересов: Авторы декларируют отсутствие конфликта интересов.

Для цитирования: Блинова А.В., Румянцев В.А. Нанотехнологии - реальность современной стоматологии (обзор литературы). Эндодонтия today. 2020; 18(2):0-0. DOI: 10.36377/1683-2981-2020-18-2-56-61.

\section{Nanotechnologies as the reality of modern dentistry (literature review)}

A.V. Blinova, V.A. Rumyantsev Federal State Budgetary Educational Institution of Higher Educational «Tver State Medical University» of the Ministry of Health of the Russian Federation, Tver, Russia

\section{Abstract}

The prefix "nano" is used by the global scientific community. Highly dispersed solidphase objects which have a size from 1 to $100 \mathrm{~nm}$ are called nanoparticles. With the international free fulltext archive «PubMed» you can get more than 215 thousand results to the "nanoparticles" search query. Today, the accumulated theoretical knowledge is being actively integrated in dentistry. Experts are thinking about new ways to solve current professional problems. Only time will tell how successful the process of integrating narrowprofile research into practical activities will be. Development and implementation of nanotechnological treatment are a promising direction for modern dentistry.

Aim was to study the promising areas for using nanotechnologies in dentistry, existing methods of diagnostics, treatment and prevention of the dental diseases based on the properties of nanoparticles, to review the scientific literature devoted to this problem.

Keywords: nanotechnology in dentistry, caries, endodontics, periodontics, immune correction, oncology, implantology.

Received: 20.02.2020; revised:15.04.2020; accepted: 09.05.2020.

Conflict of interests: The authors declare no conflict of interests.

For citation: A.V. Blinova, V.A. Rumyantsev. Nanotechnologies as the reality of modern dentistry (literature review). Endodontics today. 2020; 18(2):0-0. DOI: 10.36377/1683-2981-2020-18-2-56-61.

\section{ВВЕДЕНИЕ}

Медицина всегда была крайне восприимчива к актуальным научным веяниям. Вильгельм Рентген получил Нобелевскую премию по физике за открытие, не нуждающееся в комментариях, в 1901 году, а в 1914 году мобильные рентгеновские установки уже вовсю курсировали по фронтам Первой мировой войны. В 1953 году Уотсон и Крик расшифровали структуру ДНК - после 1960-х большинство Нобелевских премий по физиологии и медицине так или иначе были связа- 
ны с молекулярной генетикой. Схожие процессы происходят и с нанотехнологиями. Одна только реферативная база данных PubMed, знакомая многим, в ответ на поисковый запрос «nanoparticles» выдаёт более 215 тысяч результатов. Слово «нано» не несёт в себе ни негативного, ни фантастического подтекста - просто достижения физики и химии (сканирующая электронная микроскопия, темпланты, эффективные диспергенты и др.) позволили исследователям оперировать объектами в нанометровом диапазоне. Этот термин прочно вошел и в обиход стоматологов. Эндодонтия, имплантология, пародонтология, борьба с гиперестезией и рецидивирующим кариесом - вот неполный перечень проблем, которые позволяют решать современные нанотехнологии. В настоящем обзоре предпринята попытка обобщить и представить актуальные данные о работе, проводимой учёными и специалистами в этой области.

\section{Нанотехнологии в эндодонтии}

Если современная имплантология, позволяющая создавать наиболее перспективные в плане долгосрочной эксплуатации природоподобные конструкции, использует достижения нанотехнологии, чтобы предупредить воспалительные реакции отторжения имплантата, возмещающего функцию безвременно потерянного зуба, то эндодонтия борется за сохранение и эффективную реабилитацию таких зубов. В эндодонтической практике проблема борьбы с бактериальной биоплёнкой стоит крайне остро. Персистирующая в просвете многочисленных дентинных трубочек микрофлора практически неуязвима для механикомедикаментозной обработки корневых каналов. Диаметр дентинных трубочек - всего 200 - 300 нм [1], и это препятствует проникновению в них даже самых мощных антисептиков. Глубинная инфекция - провокатор осложнений и фундаментальная причина потери зубов. Использование наноразмерных частиц в составе ирригантов - передовая стратегия дезинфекции корневых каналов.

Так, в исследовании 2018 года [2] растворы наночастиц серебра и оксида цинка проявили против недельной биоплёнки E. faecalis активность, сопоставимую с эффектом 2\% раствора биглюконата хлоргексидина или 1\% гипохлорита натрия - «традиционных» ирригантов [3-5]. Ионы серебра взаимодействуют с клеточной мембраной микроорганизмов, ингибируют ферментативную систему дыхательной цепи и изменяют конформацию ДНК, нарушая процессы ее репликации [6, 7]. По другим данным, серебро переводит бактерии в так называемое состояние «nonculturable», при котором клетки сохраняют нормальную метаболическую активность, но теряют способность делиться [8]. Предпринята попытка добавить этот металл к MTA - минералтриагрегату - препарату для временного пломбирования корневых каналов [9]. Одним из вариантов контроля оральных биопленок могут стать наночастицы нитрида бора, кроме прочего, продемонстрировавшие на клетках почек собак и фибробластах человека минимальный цитотоксический эффект [10].

Исследование 2014 года продемонстрировало потенциал использования смеси пасты гидроксида кальция и наносеребра для внутриканального медикаментозного лечения [11]. В состав силеров также вводятся наночастицы: хитозана, серебра, хлоргексидина [12]. Антибиоплёночную активность проявляет оксид трёхвалентного железа [13]. Широко изучаются комплекс- ные частицы серебра и поливинилового спирта размером 4 - 11 нм, полученные методом восстановления раствора нитрата серебра в борогидриде натрия [14]. Многие исследователи сравнивают или даже комбинируют их с фарнезолом (FAR) - терпеновым спиртом, повреждающим клеточные мембраны бактерий за счет активации каспаз - протеолитических ферментов, расщепляющих белковые последовательности после аспартата [15, 16]. Колориметрический анализ показал, что и наночастицы серебра, и FAR были менее цитотоксичны, чем гипохлорит натрия. Кроме того, при проведении метода ДНК-комет оказалось, что ДНК фибробластов, обработанных экспериментальными растворами, имела более низкий процент повреждений, по сравнению с клетками, обработанными перекисью водорода [17].

\section{Гидроксид медикальция: новый взгляд} на противомикробный препарат

С конца прошлого века известен комплексный препарат - гидроксид медикальция - $\mathrm{CaCu}(\mathrm{OH}) 4$ - активно применяемый в эндодонтии. Вещество представляет собой водную пасту. Это гетерогенная равновесная система, компонентами которой являются гидроксид меди $\mathrm{Cu}(\mathrm{OH}) 2$, гидроксилионы $\mathrm{OH}$ и ионы гидроксикупрата $[\mathrm{Cu}(\mathrm{OH}) 4] 2$. Жидкая фаза, имеющая сильнощелочной $\mathrm{pH}$ и оказывающая выраженное бактерицидное действие, представляет собой стабилизированный коллоидный раствор вышеназванных частиц. Их размеры находятся в интервале от 200 до 400 нм, кроме того, путем диффузионного контакта между ними устанавливается разная степень слияния. Агрегаты частиц представлены линейными цепочками, которые могут быть зарегистрированы методом электронной микроскопии. Таким образом, высокая степень дисперсности соединения и его сложный коллоидный состав позволяют идентифицировать широкий спектр основанных на его свойствах процедур как истинные нанотехнологии.

Выраженное антибактериальное действие $\mathrm{CaCu}(\mathrm{OH}) 4$ обусловлено реакцией связывания серы из серосодержащих аминокислот бактерий и образованием плохо растворимого сульфида меди CuS. Из этого механизма следует, что действие препарата неспецифично и поливалентно.

Существует много методик применения гидроксида медикальция в стоматологической практике. Профессор Адольф Кнаппвост (Германия) первым предложил использовать его на терапевтическом приёме для лечения апикального периодонтита (сам автор назвал его «Купралом»). Он разработал метод депофореза гидроксида медикальция. Метод заключается в транспорте и депонировании вещества в корневой системе зуба с помощью постоянного электрического тока. Под действием электрического поля наночастицы перемещаются по системе дополнительных каналов и дентинным трубочкам: от макроканала к наружной поверхности корня и периапикальной зоне. Для введения Купрала в корневую систему были разработаны приборы «Оригинал II», «Комфорт», «ЭНДО 1.0» и другие. Лицензией на производство приборов и препаратов Кнаппвоста на сегодняшний день располагает немецкая фирма «Humanchemie GmbH» [18]. Несмотря на необходимость дорогостоящего оборудования и многосеансность такого лечения, метод дозированного трансканального ионофореза до сих пор интересует исследователей [19-21]. Исследова- 


\section{$58 \quad$ 06зор / Reviews}

ния 2019 года [22] подтверждают снижение интенсивности и видового разнообразия микробного пейзажа после подобного лечебного мероприятия. Предпринимаются успешные попытки его сочетания с воздействием прямого и рассеянного пучков холодной аргоновой плазмы [23].

Совершенствуя идеи А. Кнаппвоста, В.А. Румянцев с соавт. (2005) разработали метод гальванофореза [24]. В качестве источников тока в этом случае используются внутриканальные штифты, выполненные из двух металлов, составляющих гальваническую пару (например, меди и цинка). При этом на границе раздела возникает потенциал около 0,2 - 0,4 В, за счет которого заряженные частицы постепенно перемещаются из просвета корневого канала зуба в глубину дентина. Величина гальванического тока составляет около 0,1 мА. В связи с формированием в просвете дентинных трубочек конгломератов сульфида меди, изучаются возможности применения метода не только при лечении пульпита и периодонтита, но и, например, гиперестезии зубов [25, 26].

Препараты гидроксида меди-кальция предлагаются и для лечения пародонтита. Кроме антибактериального эффекта, оно опирается на свойство Купрала оказывать неглубокое прижигающее действие путём избирательного лизиса, вросшего в пародонтальный карман эпителия [18]. Немецкая фирма «Humanchemie $\mathrm{GmbH}$ » предлагает следующую методику лечения: в пародонтальные карманы с помощью гладилки или ватных турунд вносят суспензию гидроксида медикальция, для глубоких карманов используются хлопчатобумажные нити, пропитанные препаратом. Для закрепления носителей используется цианакрилатный лак. Через несколько дней их удаляют, и за счет реакции восстановления меди изначально голубые нити приобретают темнозеленую окраску.

Развивая как эндодонтическую, так и пародонтологическую «линии» терапии, В.А. Румянцев с соавт. (2018) обосновали новый способ комплексного лечения пульпопародонтальных поражений методами гальванофоретической наноимпрегнации и купралкюретажа [27]. У пациентов с хроническим апикальным периодонтитом на фоне хронического генерализованного пародонтита легкой и средней степени тяжести одновременно проводились трансканальный гальванофорез гидроксида медикальция и купралкюретаж пародонтальных карманов. Спустя 4 года наблюдений после проведенного комплексного лечения, эта методика превзошла традиционную [28] как по клиническим, так и по рентгенологическим показателям [29].

Приёмы тканевой инженерии и нанотехнологии

Нанотехнологии в пародонтологии успешно сочетаются не только с достижениями микробиологии, но и с приёмами тканевой инженерии. Так, например, сегодня единодушно признается факт того, что направленная коррекция активности популяции макрофагов в сторону противовоспалительного М2 фенотипа - ключ к патогенетическому лечению воспалительных заболеваний пародонта. С этой целью на кафедре пародонтологии Тверского государственного медицинского университета был разработан метод аутосеротерапии - подслизистых инъекций сыворотки крови, максимально обедненной клеточными элементами [30].

Китайские учёные использовали для решения этой проблемы наночастицы золота [31, 32]. Имеющие размер 45 нм, они проявили противовоспалительный потенциал в исследовании на клеточных культурах с липополисахаридом E. coli, индуцировавшем экспериментальную воспалительную реакцию. Фенотип макрофагов при этом определяли методами белкового иммуноблоттинга (обнаружение iNOS - маркера M1 фенотипа макрофагов и Arg1 - маркера M2 фенотипа) и проточной цитометрии (регистрация поверхностных маркерных белков макрофагов обоих фенотипов). Дополнительно методами ПЦР в реальном времени и ИФА определялись специфические праймеры к генаммаркерам остеогенной дифференцировки и концентрация провоспалительных факторов ФНО-а и ИЛ-6, соответственно.

В пародонтологических исследованиях в качестве носителей активного исследуемого вещества используются наночастицы полиэтиленгликоль-полилактида. Они обеспечивают доставку в зону воспаления куркумина, обладающего недостаточно удовлетворительными фармакокинетическими свойствами за счет своей гидрофобности [33], или известного иммуносупрессора ауранофина - органического производного золота [34]. Частицы полигликолевой-полимолочной кислоты в сочетании с наночастицами хитозана в соотношении 3:7 и наночастицами серебра в концентрации 50 мкг/мл в 2019 году были объединены в единый терапевтический комплекс [35]. Он не обладал выраженной цитотоксичностью и активно способствовал минерализации клеток - по данным микроскопии с красителем ализариновым красным. Комбинированные наночастицы с хитозаном и моноциклином, захватываемые микробной клеткой $\mathrm{P}$. gingivalis путём макропиноцитоза или клатринопосредованного эндоцитоза, проявляли выраженную антибактериальную внутриклеточную активность [36].

Минерализующий потенциал «нанотерапии» также высок. В исследовании, проведенном испанскими учёными, полимерные наночастицы, модифицированные кальцием и цинком, на 7 дней погружались в физиологический раствор. Осаждение аморфных минералов исследовали методом рентгеновской дифракции [37]. Подобная биомиметическая минерализация тестируемых нанокомплексов может иметь значение как для регенерации тканей пародонта, так и, например, для долгосрочного усиления сцепления на границе «дентин-пломба» [38].

\section{Нанотехнологии в перспективах диагностики}

Наночастицы используются не только для лечения, но и в качестве агентов для дополнительных методов исследования. Так, совсем недавно последним словом стоматологической техники считалась «лазерная диагностика» кариеса, основанная на оптическом явлении трансиллюминации. Исследователи из Мичиганского университета [39] использовали меченные флюоресцирующими катионами диоксифлуорана наночастицы крахмала размером 150 нм. При орошении полости рта раствором таких частиц последние легко проникали в микропоры очагов деминерализации, которые затем легко обнаруживались под светом стандартной полимеризационной галогеновой лампы. Описанная в 2017 году технология, позволяет на ранних этапах патогенеза обнаружить активно протекающий поверхностный кариес.

Онкостоматология ежедневно сталкивается с проблемой визуализации мелких отдаленных метастазов опухолей челюстно-лицевой области [40]. В клинике очаги, имеющие размер менее 5 мм, часто остаются 
невидимыми для компьютерной томографии, магнитно-резонансной и ультразвуковой диагностики. Ещё в 1895 году, изобразив на первом рентгеновском снимке руку своей жены Анны с кольцом на пальце, Вильгельм Рентген по счастливой случайности продемонстрировал рентгеноконтрастные свойства золота. С развитием эффективных химических методов синтеза наночастиц золота: восстановление золотохлористоводородной кислоты цитратом по Туркевичу, синтез золотых гидрофобных кластеров, стабилизированных монослоем алкантиола, в двухфазной водноорганической системе по Брусту-Шиффрину - радиофармпрепараты на их основе могут стать такими же доступными, как йодо- или гадолиний-содержащие [40].

Добавление лиганда, например, полиэтиленгликоля [41], способствует более длительной персистенции контраста и активной импрегнации опухолевой ткани. Существует возможность повысить специфичность наночастиц золота, снабдив их антителами к маркерным молекулам, чрезмерно экспрессируемым в кон-

\section{СПИСОК ЛИТЕРАТУРЫ:}

1. de Los Angeles Moyaho-Bernal M, Contreras-Bulnes $R$, Rodríguez-Vilchis LE, Rubio-Rosas E. Changes in deciduous and permanent dentinal tubules diameter after several conditioning protocols: In vitro study. Microsc Res Tech., 2018, Vol. 81(8), P. 865871.

2. de Almeida J., Cechella B.C., Bernardi A.V. et al. Effectiveness of nanoparticles solutions and conventional endodontic irrigants agains Enterococcus faecalis biofilm. Indian J. Dent Res., 2018, Vol. 29(3), P. 347-351.

3. Ordinola-Zapata R., Bramante C.M., Aprecio R.M. et al. Biofilm removal by $6 \%$ sodium hypochlorite activated by different irrigation techniques. Int. Endod. J., 2014, Vol. 47, P. 659-66.

4. Tong Z., Zhang Y., Wei X. The effect of human serum and dentin powder alone or in combination on the antibacterial activity of sodium hypochlorite against Enterococcus faecalis // Arch. Oral Biol., 2019, Vol.97, P. 72-76.

5. Holland R., Gomes J.E. Filho, Cintra L.T.A. et al. Factors affecting the periapical healing process of endodontically treated teeth. J. Appl. Oral Sci., 2017, Vol. 25(5), P. 465-476.

6. Durán N., Durán M., de Jesus M.B. et al. Silver nanoparticles: A new view on mechanistic aspects on antimicrobial activity. Nanomedicine, 2016, Vol. 12(3), P. 789-799.

7. Noronha V.T., Paula A.J., Durán G. Silver nanoparticles in dentistry. Dent Mater., 2017, Vol. 33(10), P. 1110-1126.

8. Königs A.M., Flemming H.C., Wingender J. Nanosilver induces a nonculturable but metabolically active state in Pseudomonas aeruginosa. Front Microbiol., 2015, Vol. 5;6, P. 395

9. Bahador A., Pourakbari B., Bolhari B., Hashemi F.B. In vitro evaluation of the antimicrobial activity of nanosilver-mineral trioxide aggregate against frequent anaerobic oral pathogens by a membraneenclosed immersion test. Biomed J., 2015, Vol. 38(1), P. 77-83.

10. Kivanç M., Barutca B., Koparal A.T. et al. Effects of hexagonal boron nitride nanoparticles on antimicrobial and antibiofilm activities cell viability. Mater. Sci. Eng. C Mater. Biol. Appl., 2018, Vol. 1;91, P. 115124.

11. Javidi M., Afkhami F., Zarei M. Efficacy of a combined nanoparticulate/calcium hydroxide root canal medication on elimination of Enterococcus faecalis. Aust. Endod. J., 2014, Vol. 40(2), P. 61-65.

12. Loyola-Rodríguez J.P., Torres-Méndez F., Espinosa-Cristobal L.F. et al. Antimicrobial activity of endodontic sealers and medications containing chitosan and silver nanoparticles against Enterococcus faecalis. J. Appl. Biomater. Funct. Mater., 2019, Vol. 17(3).

13. Sun X., Wang L., Lynch C.D. et al. Nanoparticles having amphiphilic silane containing Chlorin e6 with strong antibiofilm activity against periodontitis-related pathogens. J. Dent., 2019, Vol. 81, P. 70 84.

14. Abbaszadegan A., Nabavizadeh M., Gholami A. Positively charged imidazolium-based ionic liquid-protected silver nanoparticles: a promising disinfectant in root canal treatment. Int. Endod. J., 2015 Vol. 48(8), P. 790-800.

15. Chávez-Andrade G.M., Tanomaru-Filho M., Basso Bernardi M. Antimicrobial and biofilm antiadhesion activities of silver nanoparticles and farnesol against endodontic microorganisms for possible application in root canal treatment. Arch. Oral Biol., 2019, Vol. 107. кретных опухолях - эпидермального фактора роста EGF [42], HER2 [43], кластера дифференцировки CD24 [44] - или связав наночастицы с фолиевой кислотой, активно потребляемой опухолью [45]. Все перечисленные свойства могут принести, кроме диагностической, терапевтическую пользу, усилив эффективность лучевой [46, 47] и химиотерапии [48] опухолей полости рта, области лица и шеи.

\section{ЗАКЛЮЧЕНИЕ}

Нет никаких сомнений в том, что к нанотехнологиям стремятся приобщиться все стоматологические специальности. С одной стороны, можно подумать, что это слепое следование общемировому тренду. С другой - коллаборация с фундаментальными дисциплинами не только позволяет поддерживать благоприятный научный имидж, но и открывает множество любопытных перспектив, на которые стоит обратить внимание. Буквосочетание «нано» должно перестать удивлять современного врача-стоматолога.

16. Alves F.R., Neves M.A., Silva M.G. Antibiofilm and antibacterial activities of farnesol and xylitol as potential endodontic irrigants. Braz. Dent. J., 2013, Vol. 24(3), P. 224-9.

17. Chávez-Andrade G.M., Tanomaru-Filho M., Rodrigues E.M. et al. Cytotoxicity, genotoxi-city and antibacterial activity of poly(vinyl alcohol)-coated silver nanoparticles and farnesol as irrigating solutions. Arch. Oral Biol., 2017, Vol. 84, P. 89-93.

18. Румянцев В.А. Наностоматология: монография. М.: ООО «Медицинское информационное агентство», 2010. 192 с

19. Дерябина Л.В. Особенности применения депофореза гидроокиси медикальция при различных формах хронического периодонтита. Эндодонтия today, 2014, № 3, С. 68-71.

20. Чепурова Н.И., Романенко И.Г. Использование депофореза гидроокиси меди кальция при лечении хронического периодонтита с труднопроходимыми корневыми каналами. Вестник физиотерапии и курортологии, 2018, Т. 24, № 2, С. 120.

21. Гордеева О.В., Иваненко А.И., Старикова И.В., Радышевская Т.Н. Применение физиотерапевтических методов при эндодонтическом лечении. Colloquium-journal., 2018, № 11-2 (22), C. 61-63.

22. Саидова Л.А., Рамазонова Ш.Ш.К. Микробиологическая оценка эффективности применения депо- и апексфореза в комплексном лечении хронического верхушечного периодонтита. Молодой ученый, 2019, № 27 (265), С. 77-79.

23. Заблоцкая М.В., Митронин А.В., Заблоцкая Н.В. Лечение острого апикального периодонтита с применением метода депофореза и холодной аргоновой плазмы. Смоленский медицинский альманах, 2018, № 1, С. 109-112.

24. Румянцев В.А., Бордина Г.Е., Ольховская А.В., Опешко В.В. и др. Клинико-лабораторная оценка и обоснование способа гальванофореза гидроксида медикальция при эндодонтическом лечении апикального периодонтита. Стоматология, 2015, № 1, С. 14-19.

25. Заблоцкая Н.В., Митронин А.В., Фидарова К.Б. Электронномикроскопическая оценка эффективности лечения гиперестезии дентина путем гальванофореза гидроксида медикальция. Стоматология, 2016, Т. 95, № 6-2, С. 9-10.

26. Митронин А.В., Заблоцкая Н.В., Заблоцкая М.В. Оценка эффективности наноимпрегнационных методов лечения гиперестезии дентина зубов в экспериментальном исследовании. Эндодонтия Today, 2017, № 3, С. 22-25.

27. Румянцев В.А., Федотова Т.А., Заблоцкая М.В. и др. Новый метод комплексного лечения эндодонто-пародонтальных поражений с помощью наноимпрегнации и купрал-кюретажа. Тверской медицинский журнал, 2018, № 1, С. 34-45.

28. Силин А.В., Абрамова Н.Е., Леонова Е.В., Туманова С.А. и др. Диагностика и планирование лечения эндопародонтальных поражений. Пародонтология, 2015, № 3, С. 74- 76.

29. Румянцев В.А., Федотова Т.А., Юсупова Ю.И. и др. Эффективность эндодонтической наноимпрегнации и купрал-кюретажа в комплексном лечении эндодонто-пародонтального синдрома. Международный научно-исследовательский журнал, 2017, № 10-2 (64), С. 44-48.

30. Румянцев В.А., Авакова Д.Р., Блинова А.В. Модуляция иммунного ответа в пародонтологии и имплантологии: потенциал противовоспалительной, антибактериальной терапии и перспективные 
лекарственные формы. Обзор литературы. Пародонтология, 2019, T. 24, № 4, C. 372-377.

31. Ni C., Zhou J., Kong N. et al. Gold nanoparticles modulate the crosstalk between macrophages and periodontal ligament cells for periodontitis treatment. Biomaterials., 2019, Vol. 206, P. 115-132.

32. Zhang Y., Kong N., Zhang Y. et al. Size-dependent Effects of Gold Nanoparticles on Osteogenic Differentiation of Human Periodontal Ligament Progenitor Cells. Theranostics., 2017, Vol. 6;7(5), P. 1214 1224.

33. Zambrano L.M.G., Brandao D.A., Rocha F.R.G. et al. Local administration of curcumin-loaded nanoparticles effectively inhibits inflammation and bone resorption associated with experimental periodontal disease. Sci. Rep., 2018, Vol. 27;8(1), P. 6652.

34. Valerio M.S., Alexis F., Kirkwood K.L. Functionalized nanoparticles containing MKP-1 agonists reduce periodontal bone loss. J. Periodontol., 2019, Vol. 90(8), P. 894-902.

35. Xue Y., Hong X., Gao J. Preparation and biological characterization of the mixture of poly(lacticco-glycolic acid)/ chitosan/Ag nanoparticles for periodontal tissue engineering. Int. J. Nanomedicine., 2019, Vol. 11;14, P. 483-498.

36. Martin V., Ribeiro I.A.C., Alves M.M. et al. Understanding intracellular trafficking and anti-inflammatory effects of minocycline chitosan-nanoparticles in human gingival fibroblasts for periodontal disease treatment. Int. J. Pharm., 2019, Vol. 15; P. 572.

37. Osorio R., Alfonso-Rodríguez C.A., Medina-Castillo A.L. et al. Bioactive Polymeric Na-noparticles for Periodontal Therapy. PLoS One., 2016, Vol. 7;11(11).

38. Osorio R., Cabello I., Medina-Castillo A.L. et al. Zincmodified nanopolymers improve the quality of resindentin bonded interfaces. Clin. Oral Investig., 2016, Vol. 20(9), P. 2411-2420.

39. Jones N.A., Chang S.R., Troske W.J. Nanoparticle-Based Targeting and Detection of Microcavities. Adv. Healthc. Mater., 2017, Vol. 6(1).

\section{REFERENCES:}

1. de Los Angeles Moyaho-Bernal M, Contreras-Bulnes $R$, Rodríguez-Vilchis LE, Rubio-Rosas E. Changes in deciduous and permanent dentinal tubules diameter after several con-ditioning protocols: In vitro study. Microsc Res Tech., 2018, Vol. 81(8), P. 865871.

2. de Almeida J., Cechella B.C., Bernardi A.V. et al. Effectiveness of nanoparticles solutions and conventional endodontic irrigants against Enterococcus faecalis biofilm. Indian J. Dent Res., 2018, Vol. 29(3), P. 347-351.

3. Ordinola-Zapata R., Bramante C.M., Aprecio R.M. et al. Biofilm removal by $6 \%$ sodium hypochlorite activated by different irrigation techniques. Int. Endod. J., 2014, Vol. 47, P. 659-66.

4. Tong Z., Zhang Y., Wei X. The effect of human serum and dentin powder alone or in combination on the antibacterial activity of sodium hypochlorite against Enterococcus fae-calis // Arch. Oral Biol., 2019, Vol.97, P. 72-76.

5. Holland R., Gomes J.E. Filho, Cintra L.T.A. et al. Factors affecting the periapical healing process of endodontically treated teeth. J. Appl. Oral Sci., 2017, Vol. 25(5), P. 465-476.

6. Durán N., Durán M., de Jesus M.B. et al. Silver nanoparticles: A new view on mechanistic aspects on antimicrobial activity. Nanomedicine, 2016, Vol. 12(3), P. 789-799.

7. Noronha V.T., Paula A.J., Durán G. Silver nanoparticles in dentistry. Dent Mater., 2017, Vol. 33(10), P. 1110-1126.

8. Königs A.M., Flemming H.C., Wingender J. Nanosilver induces a non-culturable but met-abolically active state in Pseudomonas aeruginosa. Front Microbiol., 2015, Vol. 5;6, P. 395.

9. Bahador A., Pourakbari B., Bolhari B., Hashemi F.B. In vitro evaluation of the antimicro-bial activity of nanosilver-mineral trioxide aggregate against frequent anaerobic oral path-ogens by membraneenclosed immersion test. Biomed J., 2015, Vol. 38(1), P. 77-83.

10. Kıvanç M., Barutca B., Koparal A.T. et al. Effects of hexagonal boron nitride nanoparticles on antimicrobial and antibiofilm activities, cell viability. Mater. Sci. Eng. C Mater. Biol. Appl., 2018, Vol. 1;91, P. 115124.

11. Javidi M., Afkhami F., Zarei M. Efficacy of a combined nanoparticulate/calcium hydroxide root canal medication on elimination of Enterococcus faecalis. Aust. Endod. J., 2014, Vol. 40(2), P. 61-65.

12. Loyola-Rodríguez J.P., Torres-Méndez F., Espinosa-Cristobal L.F. et al. Antimicrobial ac-tivity of endodontic sealers and medications containing chitosan and silver nanoparticles against Enterococcus faecalis. J. Appl. Biomater. Funct. Mater., 2019, Vol. 17(3)

13. Sun X., Wang L., Lynch C.D. et al. Nanoparticles having amphiphilic silane containing Chlorin e6 with strong anti-biofilm activity against periodontitis-related pathogens. J. Dent., 2019, Vol. 81, P. $70-$ 84.
40. Dou Y., Guo Y., Li X. et al. Size-Tuning Ionization To Optimize Gold Nanoparticles for Simultaneous Enhanced CT Imaging and Radiotherapy. ACS Nano., 2016, Vol. 23;10(2), P. 2536-48.

41. Chhour P., Kim J., Benardo B. et al. Effect of Gold Nanoparticle Size and Coating on Labeling Monocytes for CT Tracking. Bioconjug. Chem., 2017, Vol. 18;28(1), P. 260-269.

42. Ashton J.R., Gottlin E.B., Patz E.F. et al. A comparative analysis of EGFR-targeting antibodies for gold nanoparticle CT imaging of lung cancer. PLoS One., 2018, Vol. 8;13(11).

43. Hainfeld J.F., O'Connor M.J., Dilmanian F.A. et al. Micro-CT enables microlocalisation and quantification of Her2-targeted gold nanoparticles within tumour regions. Br J Radiol., 2011, Vol. 84(1002), P. 526-533.

44. Ghaziyani M.F., Pourhassan Moghaddam M., ShahbaziGahrouei D. et al. Anti-CD24 bio Modified PEGylated Gold Nanoparticles as Targeted Computed Tomography Contrast Agent. Adv. Pharm. Bull., 2018, Vol. 8(4), P. 599-607.

45. Khademi S., Sarkar S., Shakeri-Zadeh A. et al. Targeted gold nanoparticles enable molecu-lar CT imaging of head and neck cancer: An in vivo study. Int. J. Biochem. Cell Biol., 2019, Vol. 114.

46. Park J., Park J., Ju E.J. et al. Multifunctional hollow gold nanoparticles designed for triple combination therapy and CT imaging. J. Control Release., 2015, Vol. 10;207, Vol. 77-85.

47. Liu S., Li H., Xia L. et al. Anti-RhoJ antibody functionalized Au@। nanoparticles as CT-guided tumor vessel-targeting radiosensitizers in patient-derived tumor xenograft model. Biomaterials., 2017, Vol. 141, P. $1-12$.

48. Ashton J.R., Castle K.D., Qi Y. et al. Dual-Energy CT Imaging of Tumor Liposome Deliv-ery After Gold Nanoparticle-Augmented Radiation Therapy. Theranostics., 2018, Vol. 12;8(7), P. 1782-1797.

14. Abbaszadegan A., Nabavizadeh M., Gholami A. Positively charged imidazolium-based ionic liquid-protected silver nanoparticles: a promising disinfectant in root canal treatment. Int. Endod. J., 2015, Vol. 48(8), P. 790-800.

15. Chávez-Andrade G.M., Tanomaru-Filho M., Basso Bernardi M. Antimicrobial and biofilm anti-adhesion activities of silver nanoparticles and farnesol against endodontic microorgan-isms for possible application in root canal treatment. Arch. Oral Biol., 2019, Vol. 107.

16. Alves F.R., Neves M.A., Silva M.G. Antibiofilm and antibacterial activities of farnesol and xylitol as potential endodontic irrigants. Braz. Dent. J., 2013, Vol. 24(3), P. 224-9.

17. Chávez-Andrade G.M., Tanomaru-Filho M., Rodrigues E.M. et al. Cytotoxicity, genotoxi-city and antibacterial activity of poly(vinyl alcohol)-coated silver nanoparticles and farnesol as irrigating solutions. Arch. Oral Biol., 2017, Vol. 84, P. 89-93.

18. Rumiantsev V.A. Nanodentisrty: monography. Meditsinskoe informatsionnoe agentstvo, 2010. $192 \mathrm{~s}$.

19. Deryabina L.V. Features of use depoforez of hydrooxigen copper-calcium in chronic apical periodontitis. Endodontics today, 2014, № 3, S. 68-71

20. Chepurova N.I., Romanenko I.G. The using of depoforez copper hydroxide of calcium in treatment of chronic periodontitis almost impassable root canals. Vestnik fizioterapii i ku-rortologii, 2018, T. 24, № 2, S. 120

21. Gordeeva O.V., Ivanenko A.I., Starikova I.V., Radyshevskaya T.N. Application of physio-therapeutic methods for endodontic treatment. Vestnik fizioterapii i kurortologii, 2018, T. 24, № 2, S. 120

22. Saidova L.A., Ramazonova Sh.Sh.K. Microbiological evaluation of the effectiveness of depo - and apexoforez in the complex treatment of chronic apical periodontitis. Molodoy uchenyy, 2019, № 27 (265), S. 77-79

23. Zablotskaya M.V., Mitronin A.V., Zablotskaya N.V. Treatment of acute apical periodonti-tis using depophoresis and cold argon plasma. Smolenskiy meditsinskiy al"manakh, 2018, № 1, S. 109-112

24. Rumiantsev V.A., Bordina G.E., OI'khovskaia A.V., Opeshko V.V. et al. Clinical and la-boratory rationale for galvanophoresis of hydroxide copper-calcium by root canals treat-ment. Stomatology, 2015, № 1, S. 14-19

25. Zablotskaya N.V., Mitronin A.V., Fidarova K.B. Electronmicroscopic evaluation of the effectiveness of treatment of dent hyperesthesia by copper calcium hydroxide galvanopho-resis. Stomatology, 2016, T. 95, № 6-2, S. 9-10

26. Mitronin A.V., Zablotskaya N.V., Zablotskaya M.V. The evaluation of effectiveness of nanoimpregnation in treatment of dental hyperesthesia in the settings of experimental study. Endodontics today, 2017, № 3, S. 22-25 
27. Rumyantsev V.A., Fedotova T.A., Zablotskaya M.V. et al. A new method of complex treatment of endodontal-periodontal lesions with nonimpregnated and kupral-curettage. Tverskoy meditsinskiy zhurnal 2018, № 1, S. 34-45

28. Silin A.V., Abramova N.E., Leonova E.V., Tumanova S.A. et al. Diagnosis and treatment planning for endo-perio lesions. Periodontology, 2015, № 3, S. 74- 76

29. Rumiantsev V.A., Fedotova T.A., Yusupova Yu.I., Riabikov M.D. et al. Efficiency of en-dodontic nano-impregnation and curretage with cupral in complex treatment of endodontic and periodontal syndrome. Mezhdunarodnyy nauchno-issledovatel'skiy zhurnal, 2017, № 10-2 (64), S. 44-48

30. Rumyantsev V.A., Avakova D.R., Blinova A.V. Host response modulation in periodontol-ogy and implantology: potential of antiinflammatory, antibacterial therapy and promising dosage forms Review. Periodontology, 2019, T. 24, № 4, S. 372-377

31. Ni C., Zhou J., Kong N. et al. Gold nanoparticles modulate the crosstalk between macro-phages and periodontal ligament cells for periodontitis treatment. Biomaterials., 2019, Vol. 206, P. 115-132

32. Zhang Y., Kong N., Zhang Y. et al. Size-dependent Effects of Gold Nanoparticles on Os-teogenic Differentiation of Human Periodonta Ligament Progenitor Cells. Theranostics., 2017, Vol. 6;7(5), P. 1214 1224.

33. Zambrano L.M.G., Brandao D.A., Rocha F.R.G. et al. Local administration of curcumin-loaded nanoparticles effectively inhibits inflammation and bone resorption associated with experimenta periodontal disease. Sci. Rep., 2018, Vol. 27;8(1), P. 6652.

34. Valerio M.S., Alexis F., Kirkwood K.L. Functionalized nanoparticles containing MKP-1 agonists reduce periodontal bone loss. J. Periodontol., 2019, Vol. 90(8), P. 894-902.

35. Xue Y., Hong X., Gao J. Preparation and biological characterization of the mixture of poly(lactic-co-glycolic acid)/ chitosan/Ag nanoparticles for periodontal tissue engineering. Int. J Nanomedicine., 2019, Vol. 11;14, P. 483-498.

36. Martin V., Ribeiro I.A.C., Alves M.M. et al. Understanding intracellular trafficking and an-ti-inflammatory effects of minocycline chitosan-nanoparticles in human gingival fibroblasts for periodontal disease treatment. Int. J. Pharm., 2019, Vol. 15; P. 572.

\section{ИНФОРМАЦИЯ ОБ АВТОРАХ}

Блинова А.В. - студ., ORCID ID: 0000-0002-4315-163X

Румянцев В.А. - д.м.н., профессор, зав. кафедрой пародонтологии, ORCID ID: 0000-0001-6045-3333

Федеральное государственное бюджетное образовательное учреждение высшего об-разования «Тверской государственный медицинский университет» Министерства здравоохранения Российской Федерации

\section{AUTHOR INFORMATION}

A.V. Blinova - student. ORCID ID: 0000-0002-4315-163X

V.A. Rumyantsev - doctor of medical sciences, professor, head, ORCID ID: 0000-0001-6045-3333

Department of Periodontology, Federal State Budgetary Educational Institution of Higher Education "Tver State Medical University" of the Ministry of Health of the Russian Federation

Координаты для связи с авторами / Coordinates for communication with authors:
Osorio R., Alfonso-Rodríguez C.A., Medina-Castillo A.L. et al. Polymeric Na-noparticles for Periodontal Therapy. PLoS

38. Osorio R., Cabello I., Medina-Castillo A.L. et al. Zinc-modified nopolymers improve the quality of resin-dentin bonded interfaces

40. Dou Y., Guo Y., Li X. et al. Size-Tuning Ionization To Optimize Gold Nanoparticles for Simultaneous Enhanced CT Imaging and Radiotherapy. ACS Nano., 2016, Vol. 23;10(2), P. 2536-48.

41. Chhour P. Kim J., Benardo B. et al. Effect of Gold Nanoparticle

42. Ashton J.R., Gottlin E.B., Patz E.F. et al. A comparative analysis of EGFR-targeting anti-bodies for gold nanoparticle CT imaging of lung . 2018 , Vol. 8;13(11). enables microlocalisation and quantification of Her2-targeted gold , Duraphy Contrast Agent. Adv. Pharm. Bull.

45. Khademi S., Sarkar S., Shakeri-Zadeh A. et al. Targeted gold

anoparticles designed for triple combination therapy and CT imaging. Control Release., 2015, Vol. 10;207, Vol. 77-85.

47. Liu S., Li H., Xia L. et al. Anti-RhoJ antibody functionalized Au@। nanoparticles as CT-guided tumor vessel-targeting radiosensitizers in patient-derived tumor xenograft model. Biomaterials., 2017, Vol. 141, P. $1-12$.

Ashton J.R Castle K.D., Qi Y et al. Dual-Energy CT Imaging of Tumor Liposome Delivery After Gold Nanoparticle-Augmented Radiation Therapy. Theranostics., 2018, Vol. 12;8(7), P. 1782-1797. ne., 2016, Vol. 7;11(11)

\section{Румянцев B.A. /V.A. Rumyantsev, E-mail: rumyancev_v@tvergma.ru}

